\title{
EVALUATION OF THE PROPERTIES OF HYBRID YELLOW POPLAR (Liriodendron sino-americanum): A COMPARISON STUDY WITH YELLOW POPLAR (Liriodendron tulipifera)
}

\author{
Xinhao Feng ${ }^{1}$ \\ https://orcid.org/0000-0001-7445-3158 \\ Yating Sheng ${ }^{1}$ \\ https://orcid.org/0000-0003-3825-7891 \\ Xiaowei $G e^{l}$ \\ https://orcid.org/0000-0003-2875-9740 \\ Zhihui Wu, \\ https://orcid.org/0000-0002-8207-792X \\ Qiongtao Huang $^{2}$ \\ https://orcid.org/0000-0002-4568-9919
}

\begin{abstract}
As one of the fast-growth wood species, hybrid yellow poplar (YP-h, Liriodendron sino-americanum) has been extensively planted throughout China, however, little is known about its properties and applicability in structural and nonstructural applications such as construction and furniture. The aim of this study was to evaluate the properties of YP-h and examine its differences with yellow poplar (YP, Liriodendron tulipifera). The average vessel diameter of YP-h $(55 \mu \mathrm{m})$ was $19 \%$ lower than YP $(68 \mu \mathrm{m})$, but, the density of YP-h was $37 \%$ higher than YP and the dimensional change in YP-h was higher than YP. Comparable tensile strength and flexural modulus were found in YP-h and YP, however, the flexural, shear, and impact strength of YP-h was 35 $\%, 40 \%$, and $55 \%$ higher than those of YP, respectively. The drilling, mortising, and turning processability of YP-h were superior to those of YP. Compared to the gluing and coating performance of YP, YP-h had inferior gluing properties and equivalent coating performance. Therefore, hybrid yellow poplar can be an ideal candidate for yellow poplar to be utilized in construction and furniture.
\end{abstract}

Keywords: Hybrid yellow poplar, Liriodendron sino-americanum, Liriodendron tulipifera, yellow poplar, mechanical properties. 


\section{INTRODUCTION}

Wood has been ubiquitously applied in construction, furniture, tools, and fuel for thousands of years due to its advantages of high specific strength, renewable, sustainability, attractive appearance, and ability to regulate the indoor temperature and humidity (Nguyen et al. 2018, Feng et al. 2019, Chen et al. 2020a). With the decrease of natural wood resources and increase in wood demand in China (Dai et al. 2018), the fast-growth wood species has attracted attention where the potential applications and favorable performance of wood products were achieved when the natural wood was replaced by fast-growth wood (Chen et al. 2020b). As one of the fast-growth wood species, yellow poplar (Liriodendron tulipifera) originated from eastern North America (Wang 2005, Xu et al. 2010), has been extensively used in construction (Jennings et al. 2006, Zink-Sharp and Price 2006, Ulker et al. 2018), furniture (Salca and Hiziroglu 2014), biomass (Kim et al. 2012a, Na et al. 2015, Kim and Lee 2019), bio-oil (Kim et al. 2012b), wood-based panel (Liu and Lee 2003, Shukla and Kamdem 2009), and nanofibers (Wang et al. 2020). Generally, yellow poplar needs to be physically or chemically modified to meet the application requirements, due to its disadvantages of low-density, soft, weak, and hygroscopicity (Celen et al. 2008, Chowdhury and Frazier 2013, Salca and Hiziroglu 2014, Kim and Lee 2019). Although, the yellow poplar could acclimate well to the barren and highland environment (Kim et al. 2012a), it still cannot meet the huge wood demand due to the limited importing volume and small isolated inhabitation of yellow poplar in China (Xu et al. 2010, Zhong et al. 2019). Therefore, it is imperative to develop a wood species that can be fast grown and extensively planted in China.

Hybrid yellow poplar (Liriodendron sino-americanum) derived from the hybridization of yellow poplar and Chinese tulip tree (Liriodendron chinense), was first proposed by the Chinese silviculturist Ye in 1963 (Ye 2009), and the cultivation was developed by the College of Nanjing Forest Industry in 1973 (Ye and Wang 2002). For decades, hybrid yellow poplar has shown a great capacity for fast growth and rapid production of forest products, biomass for energy, and phytoremediation in China (Li et al. 2012). It also has well adaptability in a cold and warm environments and has been widely planted throughout China, such as Beijing, Tsingtao, Xi'an, Kunming, Fujian, and Zhejiang (Shang and Wang 2012). Moreover, hybrid yellow poplar has shown preferable fiber property in pulping and machinability in furniture manufacturing (Xu 2004, Huang 2006, Jin et al. 2006).

Hybrid yellow poplar has been an ideal candidate of yellow poplar and other fast-growth wood species for producing wood-based products (Dai et al. 2004). However, its comprehensive properties including physical and mechanical properties, machinability, gluing and coating performance, have not been reported before. Therefore, in this study, the properties of hybrid yellow poplar were systematically investigated, and a comparison study was taken between hybrid yellow poplar and yellow poplar to examine their differences. Accordingly, the potential applications of hybrid yellow poplar in the construction, furniture, and wood-based products were discussed.

\section{MATERIALS AND METHODS}

\section{Materials}

Hybrid yellow poplar (YP-h, Liriodendron sino-americanum) with an average age of 10 years and diameter at breast height of $15 \mathrm{~cm}$, was purchased from Hubei Tiande Forestry Development Co., Ltd. (Jingmen, China). Yellow poplar panel (YP, Liriodendron tulipifera) with a dimension of $2500 \mathrm{~mm} \times 100 \mathrm{~mm}$ $\times 60 \mathrm{~mm}$ was supplied by Yihua Life Co., Ltd. (Shantou, China). Its average age and diameter at breast height are 10 years and $12 \mathrm{~cm}$, respectively.

\section{Optical microscopy}

Wood sample with a dimension of $10 \mathrm{~mm} \times 10 \mathrm{~mm} \times 10 \mathrm{~mm}$ was softened in water for $24 \mathrm{~h}$ and sliced by a slicer (REM710, YAMATO, Tokyo, Japan), and the thickness of the sliced sample was $20 \mu \mathrm{m}$. The sliced sample was colored with $1 \%$ aqueous safranin (Sigma-Aldrich, Shanghai, China) for 5 min at room temperature, and the anatomical structure from the cross and tangential section was observed and recorded by the light microscope (BX51, OLYMPUS, Tokyo, Japan).

The wood stick was soaked in water and heated at $70{ }^{\circ} \mathrm{C}$ until it sank at bottom of the tube. Then, the wood fiber was chemically and mechanically extracted from the wood by the method as reported in the previous 
study (Burgert et al. 2005). Briefly, the wet stick was soaked into the solution of acetic acid and hydrogen peroxide $(30 \%)$ at a volumetric ratio of $1: 1$ and heated at $70{ }^{\circ} \mathrm{C}$ for $4 \mathrm{~h}$. The stick was washed by distilled water three times and mechanically shacked to obtain the wood fiber. The fiber was colored and observed by the method mentioned above to investigate the morphology of wood fiber from YP-h and YP, respectively.

\section{Measurement of physical and mechanical properties}

The physical (density, water absorption, swelling, and shrinkage) and mechanical (flexural, tensile, shear, compressive, hardness, and impact) properties of YP-h and YP were measured according to the standards listed in Table 1.

Both specific (absolute-dried) and air-dried density of wood were measured. Water absorption was measured at $20^{\circ} \mathrm{C} \pm 2{ }^{\circ} \mathrm{C}$ for 0,$25 ; 1,2,4,8,13,20,28$, and 52 days, respectively, and the corresponding wood weight was recorded. Wood dimensions at absolute-dried, air-dried, and water saturated states were measured to calculate the tangential, radial and volumetric swelling (shrinkage) of wood. The compressive strength was measured from three directions (along the grain, tangential, and radial) at speed of $3 \mathrm{~mm} / \mathrm{min}$ and the measurement was ended when the $25 \%$ of sample thickness was compressed. The hardness was measured at cross section, tangential and radial of the sample, respectively, the steel ball with a diameter of 5,64 mm was used and the pressed depth was 5,64 $\mathrm{mm}$.

Table 1: Sample dimension, number, and referred standard for physical and mechanical measurement.

\begin{tabular}{|c|c|c|c|}
\hline Properties & Dimension $\left(\mathrm{mm}^{3}\right)$ & Number of samples & Referred standard \\
\hline Density & $20 \times 20 \times 20$ & 20 & 1 \\
\hline Water absorption & $20 \times 20 \times 20$ & 20 & 2 \\
\hline Swelling & $20 \times 20 \times 20$ & 20 & 3 \\
\hline Shrinkage & $20 \times 20 \times 20$ & 20 & 4 \\
\hline $\begin{array}{l}\text { Flexural strength } \\
\text { (modulus) }\end{array}$ & $300 \times 20 \times 20$ & 20 & 5 \\
\hline \multirow{3}{*}{$\begin{array}{l}\text { Compressive } \\
\text { strength }\end{array}$} & $30 \times 20 \times 20$ & 20 (along the grain) & 6 \\
\hline & $20 \times 20 \times 30$ & 20 (tangential) & \multirow[t]{2}{*}{7} \\
\hline & $20 \times 20 \times 30$ & 20 (radial) & \\
\hline \multirow{3}{*}{ Hardness } & $70 \times 50 \times 50$ & 20 (cross section) & \multirow[t]{3}{*}{8} \\
\hline & $50 \times 50 \times 70$ & 20 (tangential) & \\
\hline & $50 \times 50 \times 70$ & 20 (radial) & \\
\hline Impact strength & $300 \times 20 \times 20$ & 20 & 9 \\
\hline Shear strength & $40 \times 30 \times 25$ & 20 & 10 \\
\hline Tensile strength & $370 \times 20 \times 15$ & 20 & 11 \\
\hline
\end{tabular}

${ }^{1} \mathrm{~GB} / \mathrm{T} 1933$ (2009), ${ }^{2} \mathrm{~GB} / \mathrm{T} 1934.1$ (2009), ${ }^{3} \mathrm{~GB} / \mathrm{T} 1934.2$ (2009), ${ }^{4} \mathrm{~GB} / \mathrm{T} 1932$ (2009), ${ }^{5} \mathrm{~GB} / \mathrm{T} 1936.1$ (2009), GB/T 1936.2 (2009), ${ }^{6} \mathrm{~GB} / \mathrm{T} 1935$ (2009), ${ }^{7} \mathrm{~GB} / \mathrm{T} 1939$ (2009), ${ }^{8} \mathrm{~GB} / \mathrm{T} 1941$ (2009), ${ }^{9} \mathrm{~GB} / \mathrm{T} 1940$ (2009), ${ }^{10} \mathrm{~GB} / \mathrm{T} 1937$ (2009), ${ }^{11} \mathrm{~GB} / \mathrm{T} 1938$ (2009).

\section{Evaluation of machinability of wood}

The machinability of YP-h and YP wood was evaluated by measurements of planning, sanding, milling, drilling, mortising, and turning, respectively, according to the Chinese standard of LY/T 2054 (2012), in which the evaluation was taken by five grades (G-1, excellent; G-2, favorable; G-3, moderate; G-4, poor; G-5, worse). The dimension of the measured sample was $50 \mathrm{~mm} \times 50 \mathrm{~mm} \times 70 \mathrm{~mm}$ and thirty replicates were tested in every measurement. The specific process of those measurements was given below.

The wood sample was planned by a planner (SM263H, JANGJA, Shanghai, China) at spindle speed of 680 $\mathrm{rad} / \mathrm{s}$. Two levels of planning depth and three levels of feeding speed were used and listed in Table 2.

The sanding of wood was taken by a sander (1300, Chia Lung, Taiwan, China) with sandpaper of 80 mesh and $120 \mathrm{mesh}$, respectively. The feeding speed was $6,0 \mathrm{~m} / \mathrm{min}$ and the sanding thickness was $0,6 \mathrm{~mm}$. The roughness of the sanded sample was measured by a surface roughness tester (TR200, JINCHE, Zhejiang, China) with a sampling length of $0,8 \mathrm{~mm}$ and probe diameter of $5 \mu \mathrm{m}$. The testing length was $4 \mathrm{~mm}$. 
Table 2: The planning condition of wood.

\begin{tabular}{|c|c|c|}
\hline Condition & Planning depth $(\mathrm{mm})$ & Feeding speed $(\mathrm{m} / \mathrm{min})$ \\
\hline 1 & 0,8 & 8,0 \\
\hline 2 & 0,8 & 9,5 \\
\hline 3 & 0,8 & 15,0 \\
\hline 4 & 1,6 & 8,0 \\
\hline 5 & 1,6 & 9,5 \\
\hline 6 & 1,6 & 15,0 \\
\hline
\end{tabular}

The wood sample was milled by a milling machine (MX5317, NEW MAS, Guangdong, China) at spindle speed of $6000 \mathrm{r} / \mathrm{min}$. The milling was achieved within one-step molding along the wood grain and only one side of wood was milled.

The drilling was processed by a drill machine (MZ94112, NEWMAS, Guangdong, China) at spindle speed of $2800 \mathrm{r} / \mathrm{min}$. Two through-holes with diameter of $25 \mathrm{~mm}$ were drilled in every sample.

The wood mortise was produced by a slotter (YOM-120, YOW CHERNG, Taiwan, China) at spindle speed of $9500 \mathrm{r} / \mathrm{min}$. Two elliptical mortises along the wood grain were made in every sample.

The turning of wood was taken by a numerical control woodworking machine (HYMC150, HUAYE, Shandong, China) at spindle speed of $3200 \mathrm{r} / \mathrm{min}$ with a turning thickness of $8 \mathrm{~mm}$.

\section{Measurement of gluing performance}

Wood panels with smooth and clean surfaces were coated with the adhesive and compressed at pressure of 0,8 MPa for $24 \mathrm{~h}$. Samples used for gluing shear strength test, were prepared and measured according to the standard of GB/T 50329-2012, in which the sample was broken within $1 \mathrm{~min}$ at a loading speed of $2 \mathrm{~mm} /$ min and the maximum load was recorded. The wood failure area was calculated by the method provided in the standard of LY/T 2720 (2016).

\section{Measurement of coating performance}

Wood sample with a dimension of $100 \mathrm{~mm} \times 100 \mathrm{~mm} \times 10 \mathrm{~mm}$ was coated with nitrocellulose varnish and dried at room temperature for $24 \mathrm{~h}$. The coating performance including resistance to cold liquid, resistance to wet heat, resistance to dry heat, adhesion, wearability, resistance to impact, and glossiness, were measured according to the standard of GB/T 4893,1 (2013), GB/T 4893,2 (2013), GB/T 4893,3 (2013), GB/T 4893,4 (2013), GB/T4893,8 (2013), GB/T 4893,9 (2013), and GB/T 4893,6 (2013), respectively. Ten replicates were used in every condition.

\section{RESULTS AND DISCUSSION}

\section{Micro-structure and fiber morphology}

The micro-structure and fiber morphology of YP-h and YP were shown in Figure 1. Both YP-h and YP have similar micro-structure, few fillers were found in the vessel and the thickness of the vessel was thinner than the wood cell wall (Figure 1a and Figure 1b). However, the density of vessel in the cross section of YP-h was lower than that of YP, and the average vessel diameter of YP-h was $55 \mu \mathrm{m}$ which is $19 \%$ smaller than that of YP $(68 \mu \mathrm{m})$, and the cell wall of the wood fiber of YP-h was thicker than that of YP as shown in Figure 1a and Figure 1b. This is in accordance with the anatomy structure of yellow poplar in previous study (Hiraiwa et al. 2014). From the view of tangential section, the nonstoried wood ray was found in both YP-h and YP (Figure 1c and Figure 1d). Few uniseriate ray was observed and the width of wood ray was equal to the width of 2-4 wood cell in both wood. However, the maximum length of the wood ray of YP-h ( 25 wood cell) was lower than that of YP (30 wood cell). The fiber width of YP-h was similar to YP $(30 \mu \mathrm{m})$, however, its length (1258 $\mu \mathrm{m})$ was $28 \%$ shorter than that of YP $(1750 \mu \mathrm{m})$ as shown in Figure 1e and $\mathrm{f}$, and the wall thickness of fiber in YP-h $(6,33 \mu \mathrm{m})$ was $7 \%$ lower than that of YP $(6,81 \mu \mathrm{m})$. Therefore, the Runkel ratio $(2 \times$ cell wall thickness/ 
lumen width) was 0,74 and 0,91 for YP-h and YP, respectively, which demonstrates that the fiber from YP-h was more suitable for pulping than YP due to the low Runkel ratio will induce high fiber flexibility, therefore, strong tensile and anti-wrinkle strength of the paper will be obtained (Gulsoy et al. 2017).
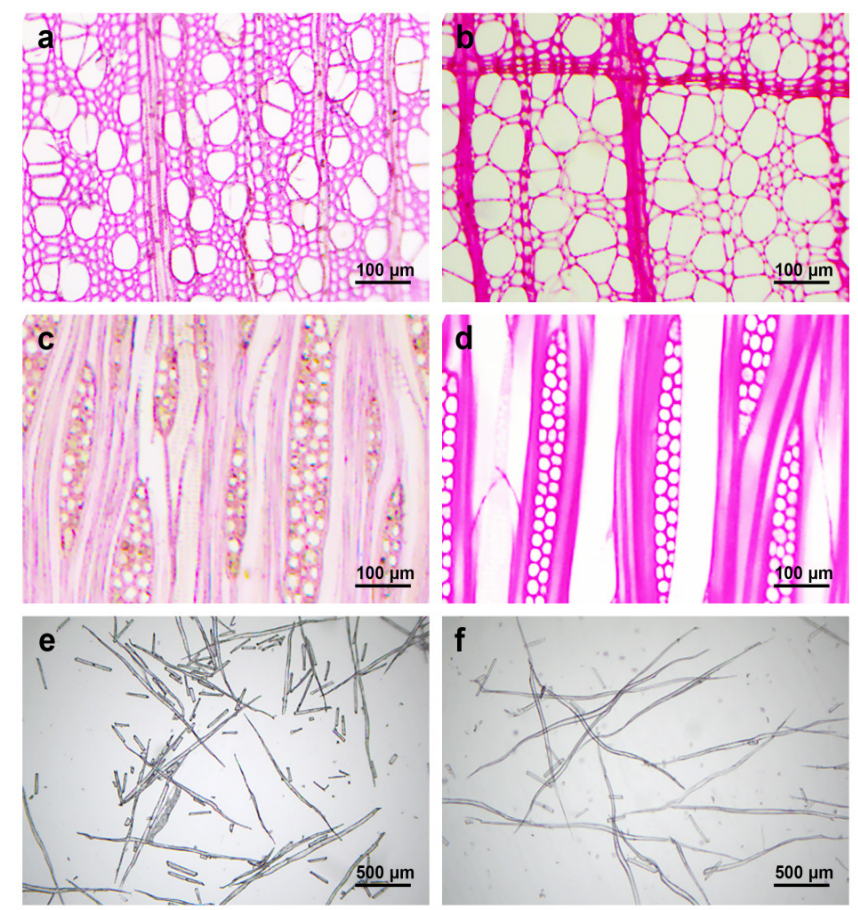

Figure 1: Anatomical structure cross section, (a) and (b); tangential section, (c) and (d) and fiber morphology (e) and f) of YP-h (a), (c), and (e) and YP (b), (d), and (f).

\section{Physical properties of wood}

The physical properties including density, water absorption, swelling, and shrinkage were shown in Figure 2 and Table 3. Both specific and air-dried density of YP-h was $37 \%$ higher than those of YP (Figure 2a), this can be verified by the micro-structure as shown in Figure 1a-d, in which the thickness of cell wall and the vessel density of YP-h was thicker and lower than those of YP, respectively. The water absorption of YP-h was faster than YP during the first 20 days due to a larger number of hydrophilic substances (e.g. cellulose) revealed by high density was contained in YP-h than YP (Fu et al. 2018). However, the water absorption of YP was compensated by high vessel density and diameter, therefore, its maximum water absorption (157\%) after 52 days was higher than YP-h (145 \%, Figure 2b). Generally, the range of wood swelling/shrinkage is volumetric $>$ tangential $>$ radial (Deklerck et al. 2019), the same phenomenon was also observed in this study as shown in Figure 2c and Figure 2d. The dimensional change (swelling and shrinkage) in YP-h was higher than that of YP independent of the wood directions (volumetric, tangential, and radial) and states (absolute-dried, air-dried, and water saturated), which demonstrates that the dimensional stability of YP-h is less than YP. 

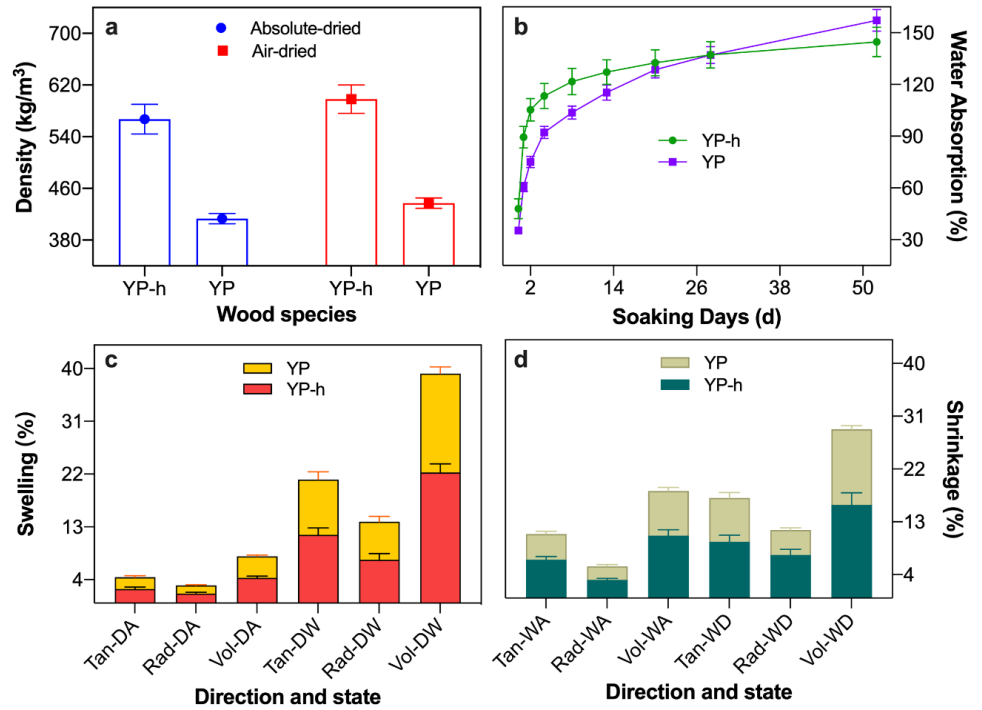

Figure 2: Density (a), water absorption (b), swelling (c), and shrinkage (d) of YP-h and YP (Tan-tangential, Rad-radial, Vol-volumetric, DA was the state transferring from absolute-dried to air-dried, DW was the state transferring from absolute-dried to water saturation, WA was the state transferring from water saturated to air-dried, WD was the opposite state of DW).

Table 3: The density, water absorption, swelling, and shrinkage of YP-h and YP.

\begin{tabular}{|c|c|c|c|c|c|c|c|}
\hline & \multicolumn{3}{|c|}{ YP-h } & \multicolumn{3}{|c|}{ YP } \\
\hline & & AVG & SD & $\begin{array}{l}\text { COV } \\
(\%)\end{array}$ & AVG & SD & $\begin{array}{l}\text { COV } \\
(\%)\end{array}$ \\
\hline \multirow{2}{*}{$\begin{array}{l}\text { Density } \\
\left(\mathrm{g} / \mathrm{cm}^{3}\right)\end{array}$} & $\begin{array}{l}\text { Absolute- } \\
\text { dried }\end{array}$ & 0,57 & 0,02 & 4,06 & 0,41 & 0,01 & 1,94 \\
\hline & Air-dried & 0,60 & 0,02 & 3,68 & 0,44 & 0,01 & 1,83 \\
\hline \multirow{9}{*}{$\begin{array}{c}\text { Water } \\
\text { absorption } \\
(\%)\end{array}$} & $0,25 \mathrm{~d}$ & 47,88 & 5,77 & 12,05 & 35,26 & 2,09 & 5,92 \\
\hline & $1 \mathrm{~d}$ & 89,43 & 6,28 & 7,02 & 60,55 & 2,68 & 4,43 \\
\hline & $2 \mathrm{~d}$ & 105,34 & 6,56 & 6,22 & 75,10 & 3,34 & 4,45 \\
\hline & $4 \mathrm{~d}$ & 113,26 & 7,36 & 6,50 & 92,15 & 3,60 & 3,90 \\
\hline & $8 \mathrm{~d}$ & 121,72 & 7,68 & 6,31 & 103,68 & 3,74 & 3,60 \\
\hline & $13 \mathrm{~d}$ & 127,18 & 7,19 & 5,65 & 115,33 & 4,45 & 3,86 \\
\hline & $20 \mathrm{~d}$ & 132,60 & 7,50 & 5,65 & 128,53 & 4,73 & 3,68 \\
\hline & $28 \mathrm{~d}$ & 137,21 & 7,70 & 5,61 & 137,10 & 4,88 & 3,56 \\
\hline & $52 \mathrm{~d}$ & 144,65 & 8,50 & 5,88 & 157,14 & 6,28 & 4,00 \\
\hline \multirow{6}{*}{$\begin{array}{c}\text { Swelling } \\
(\%)\end{array}$} & Tan-DA & 2,39 & 0,33 & 13,81 & 2,02 & 0,28 & 13,86 \\
\hline & Rad-DA & 1,62 & 0,23 & 14,20 & 1,39 & 0,12 & 8,63 \\
\hline & Vol-DA & 4,31 & 0,3 & 6,96 & 3,65 & 0,22 & 6,03 \\
\hline & Tan-DW & 11,63 & 1,17 & 10,06 & 9,43 & 1,32 & 14,00 \\
\hline & Rad-DW & 7,39 & 1,07 & 14,48 & 6,48 & 0,92 & 14,20 \\
\hline & Vol-DW & 22,27 & 1,48 & 6,65 & 16,87 & 1,12 & 6,64 \\
\hline \multirow{6}{*}{$\begin{array}{c}\text { Shrinkage } \\
(\%)\end{array}$} & Tan-WA & 6,55 & 0,54 & 8,24 & 4,35 & 0,49 & 11,26 \\
\hline & Rad-WA & 3,1 & 0,26 & 8,39 & 2,3 & 0,3 & 13,04 \\
\hline & Vol-WA & 10,64 & 1,01 & 9,49 & 7,6 & 0,61 & 8,03 \\
\hline & Tan-WD & 9,58 & 1,16 & 12,11 & 7,49 & 0,92 & 12,28 \\
\hline & Rad-WD & 7,34 & 0,96 & 13,08 & 4,27 & 0,36 & 8,43 \\
\hline & Vol-WD & 15,91 & 2,05 & 12,88 & 12,87 & 0,62 & 4,82 \\
\hline
\end{tabular}

Tan-, Rad-, Vol- is the tangential, radial, and volumetric direction of wood; DA is the state transferring from absolute-dried to air-dried; DW is the state transferring from absolute-dried to water saturation; WA is the state transferring from water saturated to air-dried; WD is the opposite state of DW; $d$ is the water absorption days; AVG is the average value; SD is the standard deviation; COV is the coefficients of variation. 


\section{Mechanical properties of wood}

Both YP-h and YP showed different mechanical behaviors in Table 4 and Figure 3. Similar tensile strength and flexural modulus were obtained in YP-h and YP, however, the flexural, shear, and impact strength of YP-h was $35 \%, 40 \%$, and $55 \%$ higher than those of YP, respectively. Moreover, the hardness of YP-h from the direction of cross section, tangential, and radial had a $17 \%, 14 \%$, and $12 \%$ increase compared to those of YP, respectively (Figure 3d, left). These improvements are mainly attributed to the high density of YP-h as shown in Figure 2a (Missanjo and Matsumura 2016). For the compressive strength (Figure 3c), the value of YP-h was 15 $\%$ lower than YP when the measurement was taken along the wood grain, which was probably attributed to the small Runkel ratio of YP-h fiber resulting in high flexibility between fibers and low compressive performance in wood (Ajuziogu et al. 2019). However, the opposite performance was observed at the direction of vertical wood grain (both in tangential and radial), in which $70 \%$ and $75 \%$ increase was found in YP-h at tangential and radial direction based on those values of YP, respectively. In short, besides the compressive strength along the wood grain, YP-h performs superior mechanical properties compared to YP. Therefore, YP-h could be an ideal candidate for YP to be applied in material engineering, especially for furniture manufacturing.

Table 4: The flexural strength and modulus, tensile strength, shear strength, compressive strength, hardness, and impact strength of YP-h and YP.

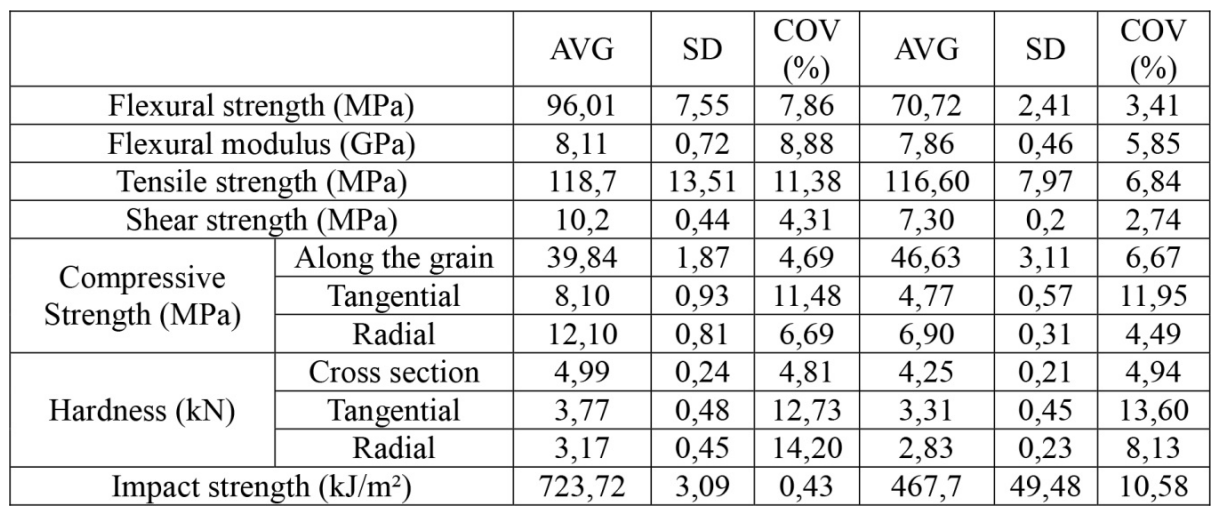

$\mathrm{AVG}$ is the average value; $\mathrm{SD}$ is the standard deviation; $\mathrm{COV}$ is the coefficients of variation
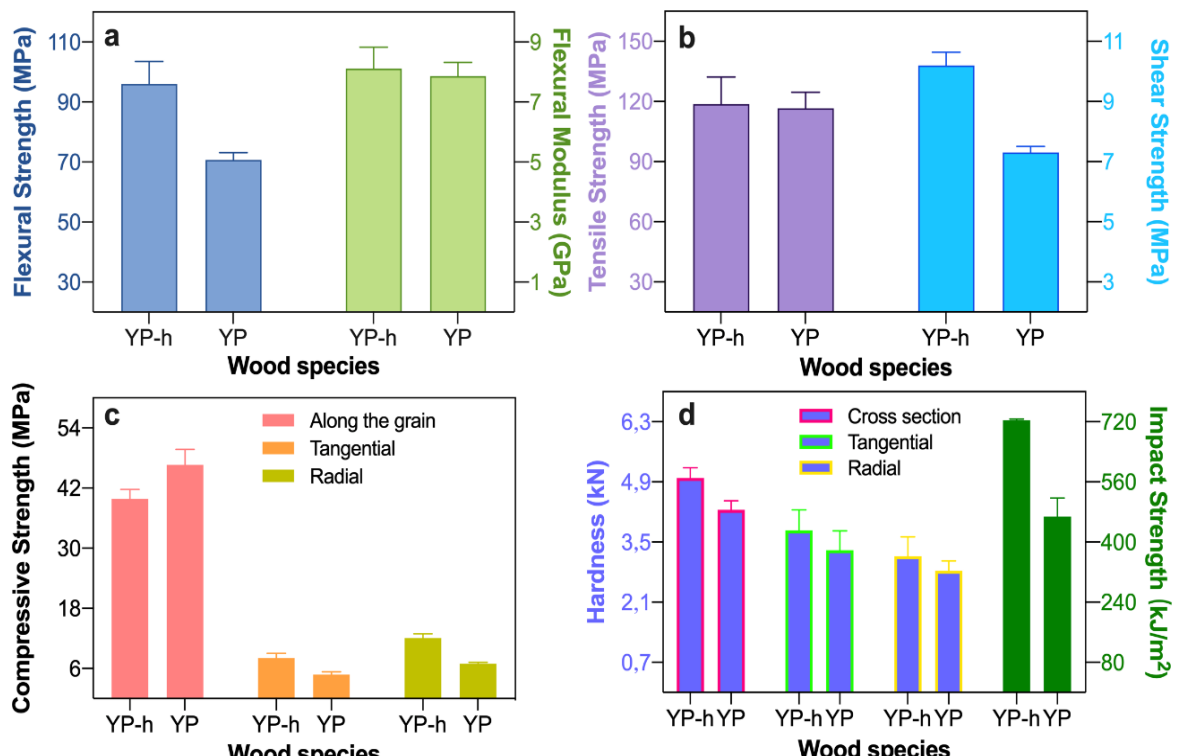

Figure 3: Flexural strength and modulus (a), tensile and shear strength (b), compressive strength (c), hardness and impact strength (d) of YP-h and YP. 


\section{Machinability of wood}

Although, YP-h has comparable physical and superior mechanical properties to YP, its processability during production still needs to be evaluated. Herein, the machinability including planning, sanding, milling, drilling, mortising, and turning of wood was measured and classified as shown in Figure 4. The planning of wood was taken under six conditions at specific planning depth and speed according to Table 2. Generally, the planning grade decreased with increasing planning depth and speed (Figure 4a). At the same planning condition, the grade of YP-h was lower than YP, in which the percentage of grade 1 (G-1) in YP-h was decreasing and other grades were increasing compared to that of YP, especially, the percentage of G-4 in YP-h significantly increased when planning was taken under condition $5(1,6 \mathrm{~mm}, 9,5 \mathrm{~m} / \mathrm{min})$ and $6(1,6 \mathrm{~mm}$, $15 \mathrm{~m} / \mathrm{min}$ ). The quality score of planned wood was calculated by weighted integral of the percentage in all five grades. It showed that YP-h had a lower quality score than YP and the score gradually decreased with increasing planning conditions (planning depth and speed). Therefore, the best a planning condition was chosen at planning depth of $0,8 \mathrm{~mm}$ and feed speed of $8 \mathrm{~m} / \mathrm{min}$, by which a superior value of $73 \%$ and $92 \%$ in G-1 was obtained for YP-h and YP, respectively. The final quality score of 4,53 for YP-h and 4,82 for YP, was achieved, which can be evaluated as "excellent" according to the standard of LY/T 2054-2012 (methods for evaluating the machining properties of lumber).

For sanding, higher sanding mesh would induce higher surface quality and lower roughness of wood (Figure 4b). Both YP-h and YP showed comparable performance, in which the percentage of G-1 was $84 \%$ for YP-h and $90 \%$ for YP and the roughness was 2,5 $\mu \mathrm{m}$ for YP-h and 2,7 $\mu \mathrm{m}$ for YP when sanding with 120 mesh. The evaluation of "excellent" can be given to both wood based on that performance in Figure $4 \mathrm{~b}$ according to the standard of LY/T 2054-2012.

The milling of both wood performed similar behavior with sanding, in which the quality of both milled wood was above G-3 and the percentage of G-1 was $87 \%$ for YP-h and $90 \%$ for YP (Figure 4c, left). Therefore, both YP-h and YP have well processability for milling. The percentage of G-2 and G-3 increased in drilling compared to those in milling (Figure 4c). As shown in Figure 4c (right), the smooth and clean morphology of drilled hole was gradually become coarse and burred from bottom to top, which is corresponding to the grade from 1 to 5 . The percentage of G-1 was $77 \%$ and $68 \%$ for YP-h and YP, respectively, demonstrating YP-h has better drilling processability than YP.
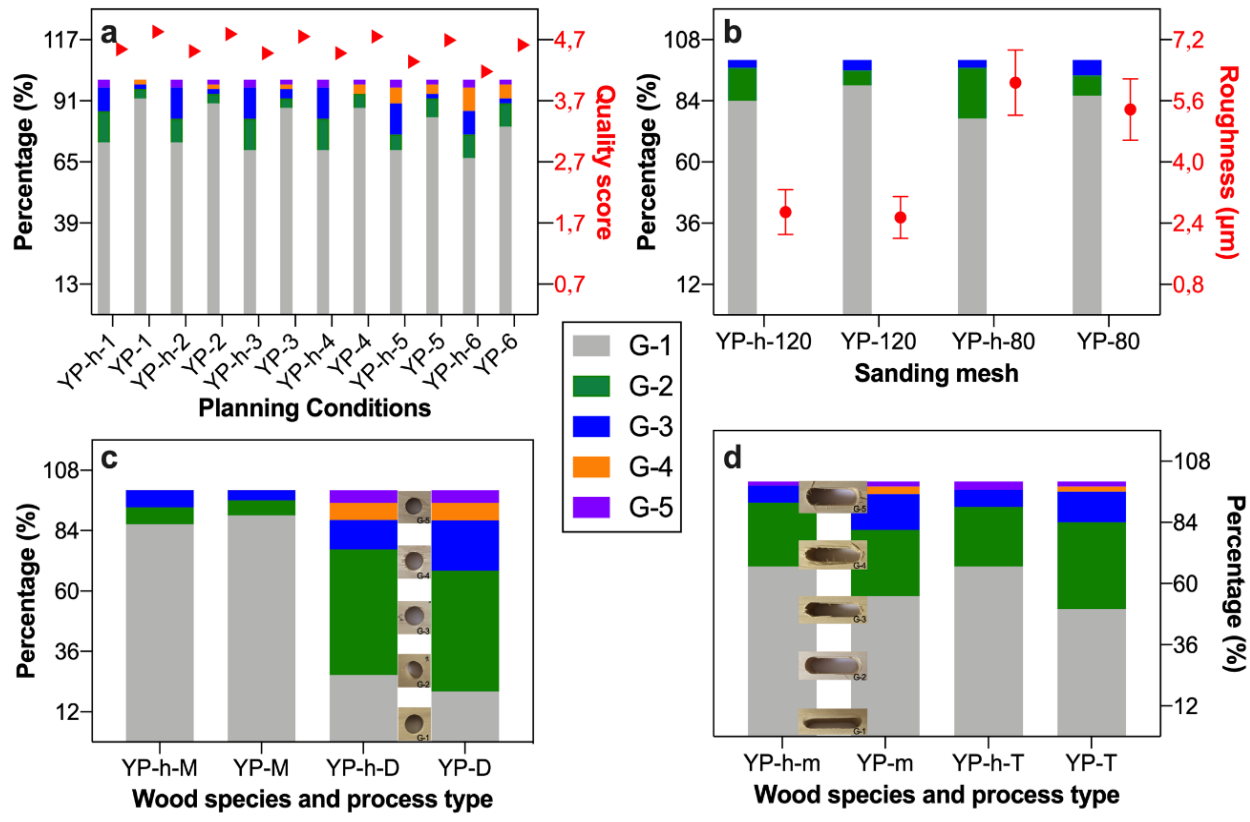

Figure 4: The properties of planning ((a), YP-h-1 6 means the corresponding planning conditions), sanding ((b), 120 and 80 are the sandpaper mesh), milling and drilling ((c), M means milling and D means drilling), mortising and turning ((d), m means mortising and T means turning) of YP-h and YP (G-1 5 are five grades used in the evaluation). 
The mortise was also gradually getting coarse and burred from smooth and clean morphology when the grade increased from 1 to 5 in both YP-h and YP (Figure 4d, left). The qualified mortise (total percentage in G-1, G-2, and G-3) in both wood was above $95 \%$ indicating the mortising of both wood can be evaluated as "excellent" according to the standard of LY/T 2054-2012. However, the percentage of G-1 was $67 \%$ and 55 $\%$ for YP-h and YP, respectively, this confirms that the mortising processability of YP-h is better than YP. The performance of turning was similar to mortising, in which both wood had a high qualified ratio ( $97 \%$ for YP-h and $96 \%$ for YP). And the percentage of G-1 was $67 \%$ for YP-h and $50 \%$ for YP indicating high turning processability of YP-h compared to YP. In conclusion, YP-h has comparable machinability with YP, especially, the drilling, mortising, and turning processability of YP-h were superior to those of YP.

\section{Gluing performance of wood}

The gluing performance of wood was evaluated by glued shear strength and wood failure area as shown in Figure 5. The average glued shear strength and wood failure area of YP-h $(9,22 \mathrm{MPa}$ and $84 \%)$ was $10 \%$ and $15 \%$ lower than those of YP $(10,22 \mathrm{MPa}$ and $99 \%)$. This probably could be attributed to the micro-structure of wood as shown in Figure 1, in which YP-h has a lower fiber slenderness ratio than YP resulting in low adhesion strength between fibers (Flores et al. 2016, Xiao et al. 2017). Although, the gluing performance of YP-h was inferior to that of YP, however, the glued shear strength and wood failure area of YP-h were higher than the minimum value of 7,8 MPa and $61 \%$ given by the standard of GB/T 50329-2012 (standard for test methods of timber structures) and GB/T 26899-2011 (structural glued laminated timber), respectively. Therefore, both the YP-h and YP can be laminated and applied in the situation with or without load bearing, such as wooden beam and furniture.

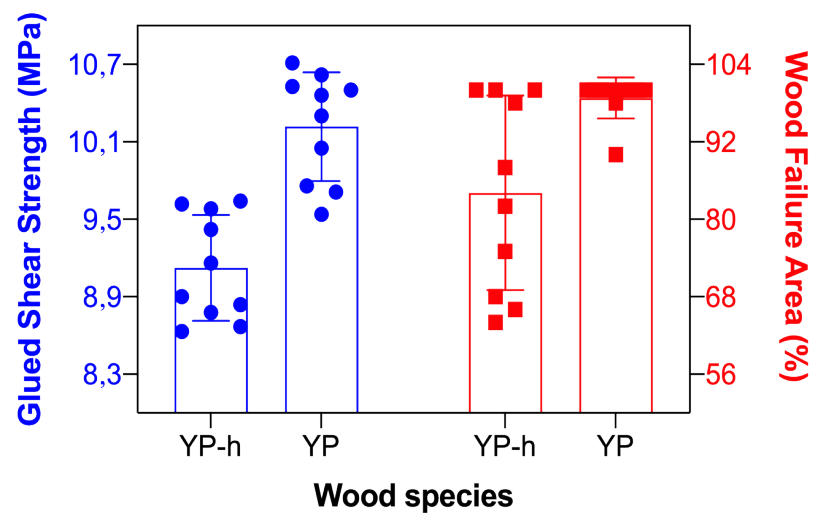

Figure 5: The glued shear strength (left) and wood failure area (right) of YP-h and YP.

\section{Coating performance of wood}

Both YP-h and YP demonstrated the same coating performance as shown in Figure 6 and Figure 7. Specifically, the appearance of coated YP-h and YP were barely changed when the cold liquid, wet heat, and dry heat was brought to the wood, respectively, indicating the resistance to cold liquid $\left(\mathrm{R}_{\mathrm{cl}}\right)$, wet heat $\left(\mathrm{R}_{\mathrm{wh}}\right)$, and dry heat $\left(\mathrm{R}_{\mathrm{dh}}\right)$ of both wood were achieved the first rating (no change, Figure 6a) and the coated YP-h can be applied in the conditions with high temperature or acid-base stains (Slabejova et al. 2018). There was little coating flaking $(<5 \%)$ on the coated YP-h and YP after adhesion measurement (Figure $6 \mathrm{~b}$ ), and this would classify the coating adhesion of YP-h and YP into the second classification. Therefore, the coated YP-h can be used to produce furniture and will perform good coating adhesion during the end-use. As shown in Figure $6 \mathrm{c}$, the wearability of coated YP-h and YP were achieved the first classification, in which no change of the coating was found after $400 \mathrm{r}$ wearing. The coating performance in resistance to the impact of YP-h and YP were below the average (Figure 6d), and there was moderate and significant damage when the impact was carried at height of $10 \mathrm{~mm}$ and $>25 \mathrm{~mm}$, respectively. This is mainly attributed to the low density of YP-h and YP, which cannot stand a comparative impact strength and result in serious damage on the coating (Chivavibul et al. 2008, Lykidis et al. 2016). The YP-h had a comparable glossiness with YP both before and after coating (Table 5 and Figure 7). The glossiness was significantly improved by coating compared to the uncoated wood. Generally, the glossiness along the grain was higher than that across the rrain (Bekhta et al. 2018), however, this discrepancy was getting less obvious after coating. For example, the glossiness of uncoated YP-h along the grain was $39 \%$ higher than that across the grain, and the difference decreased to $26 \%$ after coating. This 
indicates that the anisotropy of glossiness in both YP-h and YP was mitigated by coating as shown by the ratio between the glossiness of along and across the grain (abbreviated as $\mathrm{A}_{1} / \mathrm{A}$ ) in Figure 7 (right).
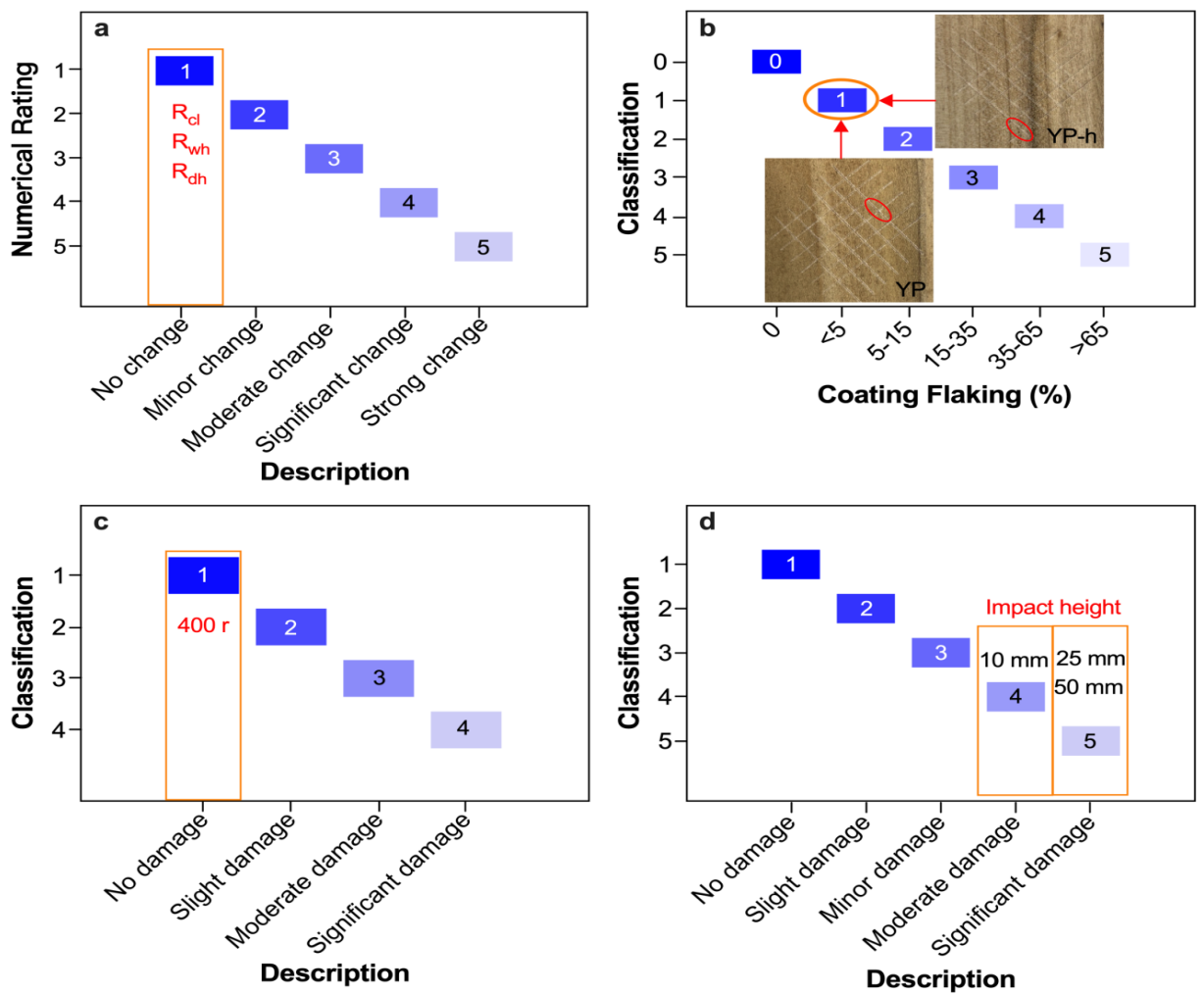

Figure 6: The coating performance of YP-h and $\mathrm{YP}$, (a) resistance to cold liquid $\left(\mathrm{R}_{\mathrm{cl}}\right)$, wet heat $\left(\mathrm{R}_{\mathrm{wh}}\right)$, and dry heat $\left(\mathrm{R}_{\mathrm{dh}}\right)$, (b) adhesion, (c) wearability, (d) resistance to impact.

Table 5: The glossiness of YP-h and YP along $\left(A_{1}\right)$ and across $\left(A_{\perp}\right)$ the wood grain $\left(A_{1} / A_{\perp}\right.$ was the glossiness ratio between $A_{1}$ and $\left.A_{\perp}\right)$.

\begin{tabular}{|c|c|c|c|c|c|c|c|c|c|}
\hline & \multicolumn{3}{|c|}{ Along the grain $\left(\mathrm{A}_{\mathrm{I}}\right)$} & \multicolumn{3}{|c|}{ Across the grain $\left(\mathrm{A}_{\perp}\right)$} & \multicolumn{3}{|c|}{$\mathrm{A}_{/} / \mathrm{A}_{\perp}$} \\
\cline { 2 - 11 } & $\begin{array}{c}\text { AVG } \\
(\%)\end{array}$ & SD & $\begin{array}{c}\text { COV } \\
(\%)\end{array}$ & $\begin{array}{c}\text { AVG } \\
(\%)\end{array}$ & SD & $\begin{array}{c}\text { COV } \\
(\%)\end{array}$ & $\begin{array}{c}\text { AVG } \\
(\%)\end{array}$ & SD & $\begin{array}{c}\text { COV } \\
(\%)\end{array}$ \\
\hline YP-h-uncoated & 7,58 & 0,63 & 8,31 & 5,45 & 0,51 & 9,36 & 1,41 & 0,02 & 1,42 \\
\hline YP-h-coated & 35,86 & 3,23 & 9,01 & 28,47 & 2,12 & 7,45 & 1,27 & 0,04 & 3,15 \\
\hline YP-uncoated & 7,07 & 0,61 & 8,63 & 4,97 & 0,43 & 8,65 & 1,41 & 0,05 & 3,55 \\
\hline YP-coated & 36,78 & 3,12 & 8,48 & 30,66 & 2,89 & 9,43 & 1,21 & 0,06 & 4,96 \\
\hline
\end{tabular}




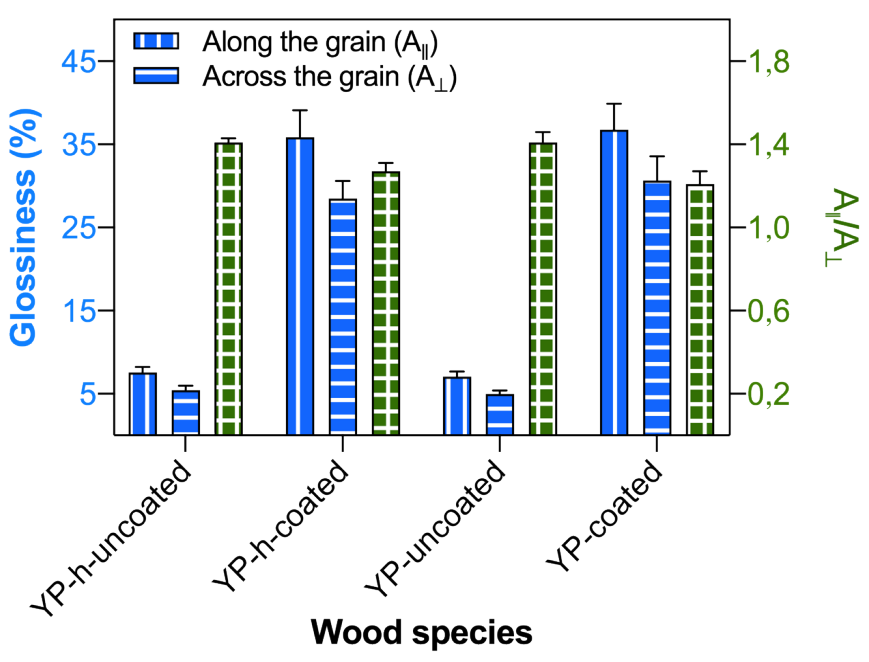

Figure 7: The glossiness of YP-h and YP along $\left(A_{\|}\right)$and across $\left(A_{\perp}\right)$ the wood grain $\left(A_{\mid} / A_{\perp}\right.$ was the glossiness ratio between $\mathrm{A}_{\|}$and $\left.\mathrm{A}_{\perp}\right)$.

\section{CONCLUSIONS}

The structural, physical, mechanical properties, machinability, gluing and coating performance of YP-h were systematically evaluated in this study. And the comparison taken between YP-h and YP demonstrated that YP-h had comparable properties with those of YP. Therefore, YP-h can be feasibly processed by traditional methods and used in structural and nonstructural applications as an ideal candidate of YP to mitigate the wood demand in China. Especially, due to the superior mechanical properties and coating performance, the YP-h can be extensively utilized in furniture manufacturing where the wood demand is continuously increasing in recent years.

\section{ACKNOWLEDGEMENTS}

This work was financially supported by the Natural Science Foundation of Jiangsu Province (BK20200779), the Natural Science Research Project of Jiangsu Colleges and Universities (19KJB220004), Youth Science and Technology Innovation Fund of Nanjing Forestry University (CX2019015), the National Natural Science Foundation of China (32071687), the Science and Technology Innovative Project between NJFU and Yihua Life (YH-MZHS-NL-201601, YH-JS-JSKF-201904002). 


\section{REFERENCES}

Ajuziogu, G.C.; Onyeke, C.C.; Ojua, E.O.; Amujiri, A.N.; Ibeawuchi, C.C. 2019. Effect of growth ring width and fiber dimensions on the compressive strength of some members of the Moraceae family. Wood Fiber Sci 51(4): 416-423. https://doi.org/10.22382/wfs-2019-039

Bekhta, P.; Krystofiak, T.; Proszyk, S.; Lis, B. 2018. Surface gloss of lacquered medium density fibreboard panels veneered with thermally compressed birch wood. Prog Org Coat 117: 10-19. https://doi.org/10.1016/j.porgcoat.2017.12.020

Burgert, I.; Fruhmann, K.; Keckes, J.; Fratzl, P.; Stanzl-Tschegg, S. 2005. Properties of chemically and mechanically isolated fibres of spruce (Picea abies L. Karst.). Part 2: Twisting phenomena. Holzforschung 59(2): 247-251. https://doi.org/10.1515/hf.2005.039

Celen, I.; Harper, D.; Labbe, N. 2008. A multivariate approach to the acetylated poplar wood samples by near infrared spectroscopy. Holzforschung 62(2): 189-196. https://doi.org/10.1515/hf.2008.048

Chen, C.; Chen, J.; Zhang, S.; Cao, J.; Wang, W.2020a. Forming textured hydrophobic surface coatings via mixed wax emulsion impregnation and drying of poplar wood. Wood Sci Technol 54(2):421-439. https://doi.org/10.1007/s00226-020-01156-7

Chen, C.; Kuang, Y.; Zhu, S.; Burgert, I.; Keplinger, T.; Gong, A.; Li, T.; Berglund, L.; Eichhorn, S. J.; Hu, L. 2020b. Structure-property-function relationships of natural and engineered wood. Nat Rew Mater 5: 642-666. https://doi.org/10.1038/s41578-020-0195-z

Chivavibul, P.; Watanabe, M.; Kuroda, S.; Komatsu, M. 2008. Evaluation of HVOF-sprayed WC-Co coatings for wood machining. Surf Coat Tech 202(21): 5127-5135. https://doi.org/10.1016/j.surfcoat.2008.05.024

Chowdhury, S.; Frazier, C.E. 2013. Compressive-torsion DMA of yellow-poplar wood in organic media. Holzforschung 67(2):161-168. https://doi.org/10.1515/hf-2011-0167

Dai, J.L.; Vendrame, W.A.; Merkle, S.A. 2004. Enhancing the productivity of hybrid yellow-poplar and hybrid sweetgum embryogenic cultures. In Vitro Cell Dev-pl 40(4):376-383. https://doi.org/10.1079/ ivp2004538

Dai, L.M.; Li, S.L.; Zhou, W.M.; Qi, L.; Zhou, L.; Wei, Y.W.; Li, J.Q.; Shao, G. F.; Yu, D.P. 2018. Opportunities and challenges for the protection and ecological functions promotion of natural forests in China. Forest Ecol Manag 410: 187-192. https://doi.org/10.1016/j.foreco.2017.09.044

Deklerck, V.; De Mil, T.; Kondjo, P.; Beeckman, H.; Van Acker, J.; Van den Bulcke, J. 2019. Sleeping beauties in materials science: unlocking the value of xylarium specimens in the search for timbers of the future. Holzforschung 73(10): 889-897. https://doi.org/10.1515/hf-2018-0269

Feng, X.H.; Wu, Z.H.; Sang, R.J.; Wang, F.; Zhu, Y.Y.; Wu, M.J. 2019. Surface design of wood-based board to imitate wood texture using 3D printing technology. Bioresources 14(4): 8196-8211. https://ojs.cnr. ncsu.edu/index.php/BioRes/article/view/BioRes_14_4_8196_Feng_Surface_Design_Wood_Board_Imitate_ Wood

Flores, E.I.S.; Saavedra, K.; Hinojosa, J.; Chandra, Y.; Das, R. 2016. Multi-scale modelling of rolling shear failure in cross-laminated timber structures by homogenisation and cohesive zone models. Int $J$ Solids Struct 81: 219-232. https://doi.org/10.1016/j.ijsolstr.2015.11.027

Fu, Q.L.; Ansari, F.; Zhou, Q.; Berglund, L.A. 2018. Wood nanotechnology for strong, mesoporous, and hydrophobic biocomposites for selective separation of oil/water mixtures. Acs Nano 12(3):2222-2230. https://doi.org/10.1021/acsnano.8b00005 
Gulsoy, S.K.; Hafizoglu, H.; Pekgozlu, A.K.; Tumen, I.; Donmez, I.E.; Sivrikaya, H. 2017. Fiber properties of axis and scale of eleven different coniferous cones. Ind Crop Prod 109: 45-52. https://doi.org/10.1016/j.indcrop.2017.07.044

Hiraiwa, T.; Aiso, H.; Ishiguri, F.; Takashima, Y.; Iizuka, K.; Yokota, S. 2014. Anatomy and chemical composition of Liriodendron Tulipifera stems inclined at different angles. IAWA J 35(4):463-475. https://doi.org/10.1163/22941932-00000078

Huang, X. 2006. Study on the processing and utilization of the hybrid tulip wood. MA.Sc. Thesis, Nanjing Forestry University. Nanjing, China. http://cdmd.cnki.com.cn/article/cdmd-10298-2006110059.htm.

Jennings, J.D.; Zink-Sharp, A.; Frazier, C.E.; Kamke, F.A. 2006. Properties of compression-densitied wood, Part II: Surface energy. J Adhes Sci Technol 20(4):335-344. https://doi.org/10.1163/156856106776381802

Jin, Y.C.; Xu, Y.; Wu, Q.B.; Pan, H.X. 2006. Kraft pulping properties of hybrid tulip tree ( $L$ chinense $x$ L tulipifera). In Research Progress in Pulping and Papermaking. Beihai, H.; Shiya, F.; Fangeng, C (eds). South China Univ Technology Press: Guangzhou, PRC. ISBN: 978-7-5623-2514-7, pp 191-194.

Kim, J.E.; Lee, J.W. 2019. Microstructural changes in the cell wall and enzyme adsorption properties of lignocellulosic biomass subjected to thermochemical pretreatment. Cellulose 26(2):1111-1124. https://doi.org/10.1007/s10570-018-2116-5

Kim, T.S.; Kim, J.Y.; Kim, K.H.; Lee, S.; Choi, D.; Choi, I.G.; Choi, J.W. 2012a. The effect of storage duration on bio-oil properties. J Anal Appl Pyrol 95: 118-125. https://doi.org/10.1016/j.jaap.2012.01.015

Kim, Y.H.; Lee, S.M.; Lee, H.W.; Lee, J.W. 2012b. Physical and chemical characteristics of products from the torrefaction of yellow poplar (Liriodendron tulipifera). Bioresource Technol 116: 120-125. https://doi.org/10.1016/j.biortech.2012.04.033

Li, T.; Chen, J.; Qiu, S.; Zhang, Y.; Wang, P.; Yang, L.; Lu, Y.; Shi, J. 2012. Deep sequencing and microarray hybridization identify conserved and species-specific microRNAs during somatic embryogenesis in hybrid yellow poplar. Plos One 7(8):e43451. https://doi.org/10.1371/journal.pone.0043451

Liu, Y.H.; Lee, A.W.C. 2003. Selected properties of parallel strand lumber made from southern pine and yellow-poplar. Holzforschung 57(2): 207-212. https://doi.org/10.1515/hf.2003.030

Lykidis, C.; Nikolakakos, M.; Sakellariou, E.; Birbilis, D. 2016. Assessment of a modification to the Brinell method for determining solid wood hardness. Mater Struct 49(3): 961-967. https://doi.org/10.1617/ s11527-015-0551-4

Missanjo, E.; Matsumura, J. 2016. Wood density and mechanical properties of Pinus kesiya Royle ex Gordon in Malawi. Forests 7(7): 135. https://doi.org/10.3390/f7070135

Na, B.I.; Ahn, B.J.; Lee, J.W. 2015. Changes in chemical and physical properties of yellow poplar (Liriodendron tulipifera) during torrefaction. Wood Sci Technol 49(2): 257-272. https://doi.org/10.1007/ s00226-014-0697-1

National Forestry and Grassland Administration. 2012. Methods for evaluation machining properties of lumber. LY/T 2054. 2012. NFGA: Beijing, China. http://hbba.sacinfo.org.cn/stdDetail/a736d3d33ddee00ec36bece98e15028e

National Forestry and Grassland Administration. 2016. Test method for wood failure percentage in adhesive bonded joints. LY/T 2720. 2016. NFGA: Beijing, China. http://hbba.sacinfo.org.cn/stdDetail/3ad0493281cc7a5da37348c9bc4452dc

Nguyen, D.M.; Grillet, A.C.; Bui, Q.B.; Diep, T.M.H.; Woloszyn, M. 2018. Building bio-insulation materials based on bamboo powder and bio-binders. Constr Build Mater 186:686-698. https://doi.org/10.1016/j. conbuildmat.2018.07.153 
Salca, E.A.; Hiziroglu, S. 2014. Evaluation of hardness and surface quality of different wood species as function of heat treatment. Mater Des 62: 416-423. https://doi.org/10.1016/j.matdes.2014.05.029

Shang, C.; Wang, Z. 2012. A new scientific name of hybrid Liriodendron-L. sino-americanum. J Nanjing Forest Univ-Sci (Natural Science Edition) 36(02):1-2. https://doi.org/10.3969/j.jssn.1000-2006.2012.02.001

Shukla, S.R.; Kamdem, D.P. 2009. Properties of laboratory made yellow poplar (Liriodendron tulipifera) laminated veneer lumber: effect of the adhesives. Eur J Wood Prod 67(4):397-405. https://doi.org/10.1007/ s00107-009-0333-1

Slabejova, G.; Smidriakova, M.; Panis, D. 2018. Quality of Silicone Coating on the Veneer Surfaces. Bioresources 13(1):776-788. https://doi.org/10.15376/biores.13.1.776-788

Standardization Administration of the People's Republic of China. 2009. Method for determination of the shrinkage of wood. GB/T 1932. 2009. SAC: Beijing, China. http://openstd.samr.gov.cn/bzgk/gb/newGbInfo?heno=543164D73BF1907C5BD71B246E009A2C

Standardization Administration of the People's Republic of China. 2009. Method for determination of the density of wood. GB/T 1933. 2009. SAC: Beijing, China. http://openstd.samr.gov.cn/bzgk/gb/newGbInfo?hcno=D3D2D1038E1A15D0A2C08A833AA69CBE

Standardization Administration of the People's Republic of China. 2009. Method for determination of the water absorption of wood. GB/T 1934,1. 2009. SAC: Beijing, China. http://openstd.samr.gov.cn/bzgk/gb/ newGbInfo?hcno=C3E8C9F67AF4B6F0312031205CDB67C1

Standardization Administration of the People's Republic of China. 2009. Method for determination of the swelling of wood. GB/T 1934,2. 2009. SAC: Beijing, China. http://openstd.samr.gov.cn/bzgk/gb/newGbInfo?heno=832DF7CC11E5117AF0CF625356BCF587

Standardization Administration of the People's Republic of China. 2009. Method of testing in compressive strength parallel to grain of wood. GB/T 1935. 2009. SAC: Beijing, China. http://openstd.samr. gov.cn/bzgk/gb/newGbInfo?hcno=34089CCF6424D8196946DBA6931F824C

Standardization Administration of the People's Republic of China. 2009. Method of testing in bending strength of wood. GB/T 1936,1. 2009. SAC: Beijing, China. http://openstd.samr.gov.cn/bzgk/gb/newGbInfo?hcno=F9DE6B9DC23FE5CE037D6A6458027F9A

Standardization Administration of the People's Republic of China. 2009. Method for determination of the modulus of elasticity in static bending of wood. GB/T 1936,2. 2009. SAC: Beijing, China. http://openstd.samr.gov.cn/bzgk/gb/newGbInfo?hcno=E9F9CF12B8898BF7958E7514442807D4

Standardization Administration of the People's Republic of China. 2009. Method of testing in shearing strength parallel to grain of wood. GB/T 1937. 2009. SAC: Beijing, China. http://openstd.samr.gov. $\mathrm{cn} / \mathrm{bzgk} / \mathrm{gb} / \mathrm{newGbInfo}$ hcno=A3E3242102355B42E4CE0B998CF309C7

Standardization Administration of the People's Republic of China. 2009. Method of testing in tensile strength parallel to grain of wood. GB/T 1938. 2009. http://openstd.samr.gov.cn/bzgk/gb/newGbInfo?hcno=54E3BE25A14818C5427ADAF48499360C

Standardization Administration of the People's Republic of China. 2009. Method of testing in compression perpendicular to grain of wood. GB/T 1939. 2009. SAC: Beijing, China. http://openstd.samr.gov. $\mathrm{cn} / \mathrm{bzgk} / \mathrm{gb} /$ new GbInfo?hcno=6B54A020E1951DF1A57EC2FA09154E1D

Standardization Administration of the People's Republic of China. 2009. Method of testing in toughness of wood. GB/T 1940. 2009. SAC: Beijing, China. http://openstd.samr.gov.cn/bzgk/gb/newGbInfo?heno=64EA96DAC191732D75C19AD2AF849528

Standardization Administration of the People's Republic of China. 2009. Method of testing in hardness of wood. GB/T 1941. 2009. SAC: Beijing, China. http://openstd.samr.gov.cn/bzgk/gb/newGbInfo $?$ hcno=AABA7A552DBD6D91817E79D3F4CEE3C2 
Standardization Administration of the People's Republic of China. 2012. Standard for test methods of timber structures. GB/T 50329. 2012 SAC: Beijing, China.

Standardization Administration of the People's Republic of China. 2013. Furniture-Assessment of surface resistance to cold liquids. GB/T 4893,1. 2013. SAC: Beijing, China. http://openstd.samr.gov.cn/bzgk/ $\mathrm{gb} /$ newGbInfo?hcno=403BF75B5FD946F58973FFE48B5A8303

Standardization Administration of the People's Republic of China. 2013. Furniture-Assessment of surface resistance to wet heat. GB/T 4893,2. 2013. SAC: Beijing, China. http://openstd.samr.gov.cn/bzgk/gb/ newGbInfo?hcno=B79E7481D06A3A63F583A4E11A5BC4E2

Standardization Administration of the People's Republic of China. 2013. Furniture-Assessment of surface to dry heat. GB/T 4893,3. 2013. SAC: Beijing, China. http://openstd.samr.gov.cn/bzgk/gb/newGbInfo?heno=24D95E9A0F2E48DECDEB842733C823C7

Standardization Administration of the People's Republic of China. 2013. Test of surface coatings of furniture - Part 4: Determination of adhesion - Cross cut. GB/T 4893,4. 2013. SAC: Beijing, China. $\mathrm{http} / / /$ openstd.samr.gov.cn/bzgk/gb/newGbInfo?hcno=87CA490E1DEAE20B420CB3AB3C21665E

Standardization Administration of the People's Republic of China. 2013. Test of surface coatings of furniture - Part 6: Determination of gloss value. GB/T 4893,6. 2013. SAC: Beijing, China. http://openstd.samr. gov.cn/bzgk/gb/newGbInfo?heno=B9A50805C3ED3375AB000A34FFDF5020

Standardization Administration of the People's Republic of China. 2013. Test of surface coatings of furniture - Part 8: Determination of wearability. GB/T 4893,8. 2013. SAC: Beijing, China. http://openstd.samr. gov.cn/bzgk/gb/newGbInfo?hcno=EB4C87D6CDAFEB5C7ABF7B9A2FD5B7F3

Standardization Administration of the People's Republic of China. 2013. Test of surface coatings of furniture - Part 9: Determination of resistance to impact. GB/T 4893,9. 2013. SAC: Beijing, China. http://openstd.samr.gov.cn/bzgk/gb/newGbInfo?heno=FDB430DFB80C0E8DC82D3013F8CF585A

Ulker, O.; Aslanova, F.; Hiziroglu, S. 2018. Properties of thermally treated yellow poplar, southern pine, and eastern redcedar. Bioresources 13(4):7726-7737. https://doi.org/10.15376/biores.13.4.7726-7737

Wang, X.; Chen, H.; Feng, X.; Zhang, Q.; Labbe, N.; Kim, K.; Huang, J.; Ragauskas, A. J.; Wang, S.; Zhang, Y. 2020. Isolation and characterization of lignocellulosic nanofibers from four kinds of organosolv-fractionated lignocellulosic materials. Wood Sci Technol 54(3):503-517. https://doi.org/10.1007/ s00226-020-01167-4

Wang, Z. 2005. Utilization and species hybridization in Liriodendron. Chinese Forestry Press: Beijing.

Xiao, Y.; Wu, Y.; Li, J.; Yang, R.Z. 2017. An experimental study on shear strength of glubam. Constr Build Mater 150: 490-500. https://doi.org/10.1016/j.conbuildmat.2017.06.005

Xu, C. 2004. Study on the wood properties of the hybrid tulip tree. MA.Sc. Thesis, Nanjing Forestry Univeristy. Nanjing, China. http://cdmd.cnki.com.cn/article/cdmd-10298-2004092233.htm.

Xu, M.; Sun, Y.; Li, H.2010. EST-SSRs development and paternity analysis for Liriodendron spp. New Forest 40(3):361-382. https://doi.org/10.1007/s11056-010-9205-0

Ye, H. 2009. Peizhong Ye. Chinese Forestry Press: Beijing. China.

Ye, J.; Wang, Z. 2002. Genetic analysis of heterosis for hybrid tulip tree. Scientia Silvae Sinicae 38(04):6771. https://doi.org/10.11707/j.1001-7488.20020411

Zhong, Y.D.; Yang, A.H.; Liu, S.J.; Liu, L.P.; Li, Y.Q.; Wu, Z.X.; Yu, F.X. 2019. RAD-Seq data point to a distinct split in Liriodendron (Magnoliaceae) and obvious east-west genetic divergence in L. chinense. Forests 10(1):13. https://doi.org/10.3390/f10010013 